\title{
A MONITORING SYSTEM FOR SUSTAINABLE URBAN MOBILITY PLANS
}

\author{
JONAS DAMIDAVIČIUS ${ }^{*}$, MARIJA BURINSKIENÉ², \\ RASA UŠPALYTĖ-VITKŪNIENE ${ }^{3}$ \\ ${ }^{1,2,3}$ Dept of Roads, Vilnius Gediminas Technical University, \\ Vilnius, Lithuania
}

Received 08 April 2019; accepted 08 May 2019

\begin{abstract}
Sustainable Urban Mobility Plans are developed in Europe rapidly. The future initiative is expected to change the image of European cities and will make transport systems efficacious, thus reducing congestion, decreasing air pollution, and offering alternative options for travelling. The impact of the measures being implemented needs to be monitored regularly to evaluate the effect of Sustainable Urban Mobility Plans, and progress in accomplishing the objectives and specific aims of Sustainable Urban Mobility Plans are assessed. Infrastructure measures often require considerable investment, and therefore, their rational use expected to create immense benefit to the public. This article analyses various European models for monitoring and evaluating Sustainable Urban Mobility Plans. The models are structured, proposing an assessment methodology for Sustainable Urban Mobility Plans. Assistance provided by the experts and the use of evaluation models for the analytic hierarchy process assists in identifying the significance of the monitoring indicators that allow assessing the priority orders and the importance of implementing mobility measures.
\end{abstract}

Keywords: analytic hierarchy process, evaluation, mobility, monitoring, Sustainable Urban Mobility Plan (SUMP).

* Corresponding author. E-mail: jonas.damidavicius@vgtu.lt 


\section{Introduction}

Planning sustainable and efficient transport systems crucial to reducing the impact on climate change and contribution to the aims of decreasing pollutants were set in 2015 by signing the Paris Declaration (United Nations Framework Convention on Climate Change, 2015). For changes in the existing dependence on the use of fossil fuels and a reduction in carbon emissions, a strategic and integrated planning approach is necessary. Ensuring efficient, inclusive and climatefriendly urban transport infrastructure is essential for developing high functioning and competitive cities/towns. In recent years, with reference to White Paper "Roadmap to a Single European Transport Area - Towards a Competitive and Resource Efficient Transport System" (White Transport Paper) (European Commision, 2011) and Communication from the Commission to the European Parliament, the Council, the European Economic and Social Committee and the Committee of the Regions "Together Towards Competitive and Resource - Efficient Urban Mobility" (Communication of Efficient Urban Mobility) (European Commision, 2013), a solid theoretical foundation of Sustainable Urban Mobility Plans (SUMPs) have emerged in Europe. Long-term integrated thinking in planning urban transport systems is one of the most important goals must be attained in the daily activities of all stakeholders.

The fundamental principles of successful sustainable mobility planning cover the involvement of public and stakeholders in the process of planning and implementing SUMPs; promoting institutional cooperation dealing with the issues of transport interaction with other aspects of urban life; selecting the most efficient urban mobility measures; monitoring and evaluating the measures and implementation process of SUMPs. The process of monitoring and evaluation has been insufficiently analysed and is rarely applied in practice, which is the challenge for cities/towns in the successful implementation of SUMPs.

Monitoring and evaluation provide information on the progress of the planning and implementation process and the design or expected impact of the selected mobility measures. As a result, monitoring and evaluation indicators be obliged to set in the process of planning and implementing SUMPs; following the realisation process, appropriate decisions on further implementation measures should be taken, taking into account monitoring data. Planners and decision-makers identify emerging problems, potential success or the need to re-examine certain SUMP domains on the resulting data timely. Monitoring and evaluation practices are very different among European countries, and lack of experience, inadequate funding and poor inter-institutional cooperation are the causes of the ineffective monitoring and evaluation process.
Ušpalytè-Vitkūnienè

A Monitoring

System

for Sustainable

Urban Mobility

Plans 
Different sources present various recommendations for the successful integration of monitoring and evaluation into the planning process. The accurate summary of different recommendations has been made within the implemented project "Challenge - Addressing Key Challenges of Sustainable Urban Mobility Planning" funded by the EU Programme Intelligent Energy Europe (2016). The project describes in detail six steps proposed for the successful evaluation and monitoring of SUMPs:

- proper procedures for monitoring and evaluating implementation progress and impact;

- a precise formulation of SUMP objectives identifying deadlines for evaluation, defining political interests and setting the starting point (start of measurement);

- raising the critical issues in the evaluation and monitoring plan, setting targets and data evaluation methods that should allow finding the answers whether SUMP results correspond to the set goals;

- evaluating preparing the SUMP process;

- applying a systematic approach to the selection of evaluation indicators, which reflect the objectives of SUMPs and allow a thorough assessment of progress in the impact of implementation (choosing evaluation indicators should be carried out in conjunction with other relevant authorities);

- specifying the analysis, evaluation and presentation of the collected data.

The critical point is to carry out the monitoring and evaluation process properly. A large number of targets are redundant, as only a few of those, accurately reflecting the objectives of SUMPs are enough. Selecting targets also depends mostly on the type (capital, regional centre, resort, industrial area) and size (population above 100 000, from 20000 to 100000 and 20000 ) of the city or town.

The article focuses on the reasoned classification of indicators for evaluating and monitoring sustainable urban mobility and assigns them to a particular target and the thematic area after a thorough analysis of practical studies and methods used in foreign countries. This allows an accurate assessment of SUMP objectives. After the unification of the methodology for monitoring the implementation of SUMPs, results are possible to evaluate and compare the impacts between the implemented measures in different places. For this article, the experts will determine significances subject to the type and size of the city/town. The targets priority order will help in evaluating priority areas and will allow rational planning or monitoring the impact of sustainable mobility measures. 


\section{The selection of indicators and the development of monitoring and evaluation targets}

The research literature guides the criteria used for selecting evaluation and monitoring indicators. Several authors noted that indicator selection ought to be primarily driven by the questions the indicators were supposed to answer (Joumard, Gudmundsson, \& Folkeson, 2011; Li, Liu, Hu, Wang, Yang, Li, \& Zhao, 2009; Litman, 2010, 2007; Zhang \& Guindon, 2006). The indicator has to be easily understandable, reasonable, measurable, possible to quantify, accessible, comprehensive, reflect various aspects of study, sensitive to changes over time, independent, standardized for comparison, clearly defined and capture long-term processes ( $\mathrm{Li}, \mathrm{Liu}, \mathrm{Hu}$, Wang, Yang, Li, \& Zhao, 2009; Litman, 2010, 2007; Nourry, 2008; Zhang \& Guindon, 2006).

In Chapter 4 of their recent research, Joumard, Gudmundsson, \& Folkeson (2011) introduce ten criteria for selecting indicators falling in three main categories:

- representation - validity, reliability, sensitivity;

- operation - measurability, data availability, ethical concerns;

- policy application - transparency, interpretability, target relevance, acting ability.

Haghshenas \& Vaziri (2012) proposed using seven criteria for selecting evaluation indicators:

- target relevance - each indicator must show one aspect of sustainable transportation;

- data availability and measurability - indicators must be measurable with the International Association of Public Transport (UITP) database;

- validity - indicators must measure the issue it is supposed to measure;

- $\quad$ sensitivity - indicators must reveal sustainable transport changes in cities/towns;

- transparency - indicators need to be feasible to understand and possible to reproduce for the intended users;

- independent - the indicators need to be independent of each other;

- standardised - indicator should be standardised by city size for cities comparison.

The criteria for the latter system are clear and accurately defining requirements for setting evaluation indicators; however, it should be noted that the global urban transportation database UITP Millennium Cities Database for Sustainable Mobility available at the UITP has prepared this system for criteria (Vivier, Kenworthy, \& Laube, 2001). 
Therefore, the criterion Data Availability and Measurability possible to replace with the system or database applied in the evaluated and monitored area, for instance, data from the city traffic control centre.

To provide a detailed description of each evaluation indicator, Karagiannakidis, Sdoukopoulos, Gavanas, \& Pitsiava-Latinopoulou (2014), suggested filling in a technical table of indicators, the information contained in Table 1 allow knowing exactly how the indicator evaluated and what methods for data collection possible to use.

A comparative Table 2 defining the abundance of evaluation indicators have been developed after analysis of 16 research sources, projects and strategies describing evaluation indicators for assessing the impact of sustainable urban mobility. Four hundred fifty-three evaluation indicators, some of them are repeated, or similarly formulated in different sources have been identified in the analysed material.

In most cases, evaluation indicators for each source have been classified or distinguished by a specific target such as evaluation indicator Death and Injuries from Transport. Mameli \& Marletto (2014)

Table 1. The example of a technical report on the indicator (Karagiannakidis, Sdoukopoulos, Gavanas, \& Pitsiava-Latinopoulou, 2014)

\begin{tabular}{|c|c|}
\hline Indicator & Description \\
\hline Name & Share of traffic calming roads \\
\hline Description & $\begin{array}{l}\text { Roads with traffic calming measures as a share of the } \\
\text { total length of the road network }\end{array}$ \\
\hline $\begin{array}{l}\text { Methodological } \\
\text { approach }\end{array}$ & $\begin{array}{l}\text { a) Analysis of the base map of the study area; } \\
\text { b) Measurement of the total length of the road } \\
\text { network; } \\
\text { c) Measurement of the total length of roads with } \\
\text { traffic calming measures; } \\
\text { d) Division of the total length of roads with traffic } \\
\text { calming measures by the total length of the road } \\
\text { network. }\end{array}$ \\
\hline Unit & $\%$ \\
\hline $\begin{array}{l}\text { Calculation } \\
\text { frequency }\end{array}$ & $\begin{array}{l}\text { Short-term ( } 2 \text { years) } \\
\text { Medium-term ( } 5 \text { years) } \\
\text { Long-term ( } 10 \text { years })\end{array}$ \\
\hline Policy goal & $\begin{array}{l}\text { Efficient traffic management - Increased road safety - } \\
\text { Promotion of Active Transport }\end{array}$ \\
\hline Spatial reference & Regional unit, Municipality \\
\hline Data sources & General directorate for technical services \\
\hline
\end{tabular}


Table 2. Information related to 16 sources

\begin{tabular}{|c|c|c|c|}
\hline No. & References & Authors & $\begin{array}{c}\text { Number } \\
\text { of Indicators }\end{array}$ \\
\hline 1 & $\begin{array}{l}\text { Indicators to Assess the Sustainability } \\
\text { of Transport Activities }\end{array}$ & $\begin{array}{l}\text { Dobranskyte-Niskota, Perujo, } \\
\text { \& Pregl (2008) }\end{array}$ & 36 \\
\hline 2 & $\begin{array}{l}\text { City of York's Third Local Transport Plan } \\
\text { 2011-2031 }\end{array}$ & City of York Council (2011) & 22 \\
\hline 3 & $\begin{array}{l}\text { Measuring the sustainability of transport } \\
\text { in the city - development of an indicator-set }\end{array}$ & $\begin{array}{l}\text { Olofsson, Varhelyi, Koglin, } \\
\text { \& Angjelevska (2011) }\end{array}$ & 85 \\
\hline 4 & $\begin{array}{l}\text { Indicators for sustainable urban mobility - } \\
\text { Norwegian relationships and comparisons }\end{array}$ & $\begin{array}{l}\text { Nenseth Christiansen, \& Hald, } \\
\text { (2012) }\end{array}$ & 29 \\
\hline 5 & $\begin{array}{l}\text { Urban sustainable transportation indicators } \\
\text { for global comparison }\end{array}$ & Haghshenas \& Vaziri (2012) & 24 \\
\hline 6 & $\begin{array}{l}\text { Developing an indicator system for local } \\
\text { governments to evaluate transport } \\
\text { sustainability strategies }\end{array}$ & Shiau \& Liv (2013) & 19 \\
\hline 7 & $\begin{array}{l}\text { Can National Survey Data be Used to Select } \\
\text { a Core Set of Sustainability Indicators } \\
\text { for Monitoring Urban Mobility Policies? }\end{array}$ & Mameli \& Marletto (2014) & 14 \\
\hline 8 & $\begin{array}{l}\text { The Future of Urban Mobility 2.0: } \\
\text { Imperatives to Shape Extended Mobility } \\
\text { Ecosystems of Tomorrow }\end{array}$ & $\begin{array}{l}\text { Van Audenhove, Korniichuk, } \\
\text { Dauby, \& Pourbaix (2014) }\end{array}$ & 23 \\
\hline 9 & $\begin{array}{l}\text { How to Monitor Sustainable Mobility in Cities? } \\
\text { Literature Review in the Frame of Creating } \\
\text { a Set of Sustainable Mobility Indicators }\end{array}$ & $\begin{array}{l}\text { Gillis Semanjski, \& Lauwers, } \\
\text { (2016) }\end{array}$ & 20 \\
\hline 10 & CH4LLENGE project & $\begin{array}{l}\text { Intelligent Energy Europe } \\
\text { (2016) }\end{array}$ & 44 \\
\hline 11 & $\begin{array}{l}\text { Indicator-based evaluation of sustainable } \\
\text { transport plans: a framework for Paris } \\
\text { and other large cities }\end{array}$ & Chakhtoura \& Pojani (2016) & 28 \\
\hline 12 & CIVITAS CAPITAL project & CIVITAS (2016) & 28 \\
\hline 13 & $\begin{array}{l}\text { Evaluation of sustainable urban mobility } \\
\text { in the city of Thessaloniki }\end{array}$ & $\begin{array}{l}\text { Perra, Sdoukopoulos, } \\
\text { \& Pitsiava-Latinopoulou (2017) }\end{array}$ & 23 \\
\hline 14 & $\begin{array}{l}\text { Successful Sustainable Mobility Measures } \\
\text { Selection }\end{array}$ & $\begin{array}{l}\text { Burinskienè, Gaučè, } \\
\text { \& Damidavičius (2017) }\end{array}$ & 37 \\
\hline 15 & Lithuanian General Plan 2030 & $\begin{array}{l}\text { Ministry of Environmental } \\
\text { of the Republic of Lithuania } \\
(2018 a)\end{array}$ & 13 \\
\hline 16 & Lithuanian sustainable development goals & $\begin{array}{l}\text { Ministry of Environmental } \\
\text { of the Republic of Lithuania } \\
(2018 b)\end{array}$ & 8 \\
\hline
\end{tabular}


assessed the target Increase in Safety. Shiau \& Liu (2013) evaluated the same indicator considering the target Reduction in the Number of Injuries and Fatalities. A single indicator on its own does not show the impact a mobility measure because most frequently are used quantitative indicators (as Length of Bike Paths in Kilometres, Number of the Restructured Public Transport Stops and so on). Fewer applied qualitative indicators, for example, Density of Intermodal Interchanges, Capacity of Park and Ride Facilities, Yearly Delay per Car Commuter. The assessment of the overall impact of indicators is necessary to evaluate the impact of mobility measures on the transport system and the mobility of people. The analysis of all 16 sources and the created system for recurring and similar indicators proposed 24 targets, which covered analogous evaluation indicators combining them into one group (Table 3). By the

Table 3. Targets for monitoring and evaluation

\begin{tabular}{|c|c|c|c|}
\hline No & Target & No & Target \\
\hline T1 & Accessibility to the main services & $\mathrm{T} 13$ & $\begin{array}{l}\text { Mobility management (occupancy/length, } \\
\text { number, time of trips/traffic speed, intensity) }\end{array}$ \\
\hline $\mathrm{T} 2$ & $\begin{array}{l}\text { Adaptation of intelligent } \\
\text { transport systems }\end{array}$ & T14 & Modal share \\
\hline T3 & $\begin{array}{l}\text { Cost recovery for transport } \\
\text { investments }\end{array}$ & T15 & Motorisation level \\
\hline T4 & $\begin{array}{l}\text { Cost recovery for transport } \\
\text { operations }\end{array}$ & T16 & Reduction in accidents by mode \\
\hline T5 & $\begin{array}{l}\text { Development of non-motor } \\
\text { infrastructure }\end{array}$ & T17 & Reduction in greenhouse gas emissions \\
\hline T6 & Improvements in air quality & T18 & $\begin{array}{l}\text { Reduction in the killed and seriously injured } \\
\text { persons in traffic }\end{array}$ \\
\hline $\mathrm{T7}$ & $\begin{array}{l}\text { Increase in the attractiveness } \\
\text { of the street environment }\end{array}$ & T19 & Reducing noise \\
\hline T8 & Increase in economic growth & $\mathrm{T} 20$ & Reduction in traffic congestions \\
\hline T9 & $\begin{array}{l}\text { Increase in public transport } \\
\text { attractiveness, accessibility } \\
\text { and affordability }\end{array}$ & $\mathrm{T} 21$ & $\begin{array}{l}\text { Reduction in urban space consumption } \\
\text { for transport infrastructure }\end{array}$ \\
\hline T10 & $\begin{array}{l}\text { Increase in the quality } \\
\text { of the available transport } \\
\text { infrastructure }\end{array}$ & T22 & The satisfaction of the transport system \\
\hline T11 & $\begin{array}{l}\text { Increase in renewable energy } \\
\text { usage in transport }\end{array}$ & T23 & Share of multimodal trips \\
\hline $\mathrm{T} 12$ & Management of parking spaces & T24 & Share of streets with traffic calming measures \\
\hline
\end{tabular}


analysed sources identified evaluation indicators, 24 suggested targets (Figure 1) recurring in several sources (Figure 1) were calculated.

Targets are assigned to appropriate thematic areas (one or more of those) to facilitate the monitoring and evaluation of sustainable urban mobility in individual sections and to provide more informative and more precise findings.

The principal scheme for the structure of SUMP evaluation indicators and targets is shown in Figure 2.

Targets are unequally important, therefore the assigned thematic areas will allow identifying the targets, indicators need to be given more considerable attention, and those are less important and relevant than others considering the type and size of the city/town.

Lithuanian Guidelines use thematic areas and their definitions on the Preparation of Sustainable Urban Plans, which include nine thematic areas forming the whole foundation of the SUMP (Ministry of Transport and Communications of the Republic of Lithuania, 2015):

- Promotion of Public Transport (H1);

- Non-Motor Vehicle Integration (H2);

- Modal Shift (H3);

- Traffic Safety and Transport Security (H4);

- Improvement in Traffic Organization and Mobility Management (H5);

- City Logistics (H6),

- Integration of People with Special Needs (H7);

- Promotion of Alternative Fuels and Clean Vehicles (H8);

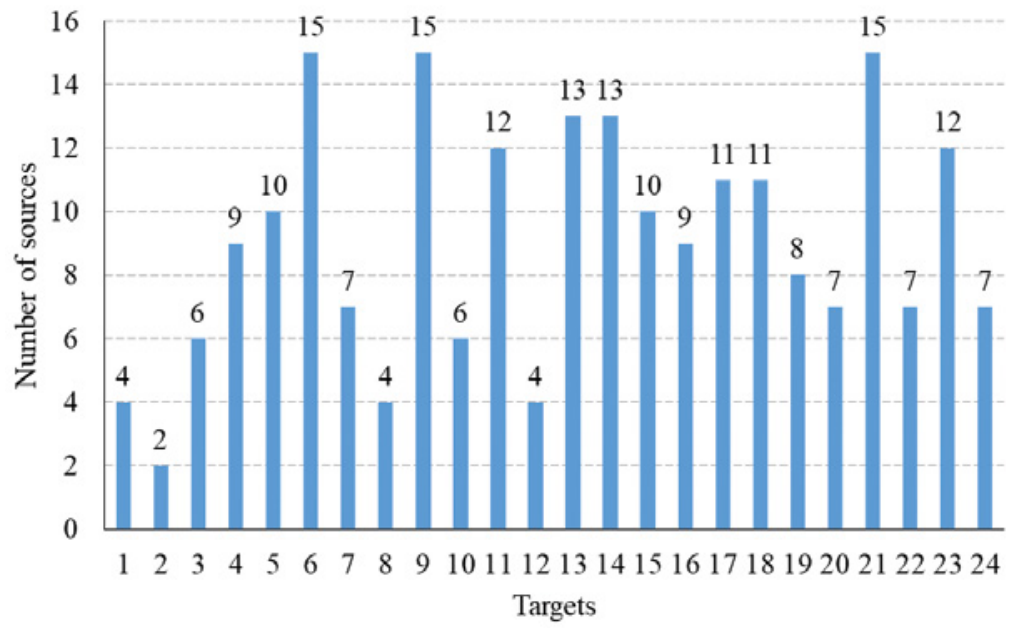

Figure 1. The number of sources repeated in targets
Jonas Damidavičius, Marija Burinskienè,

Rasa

Ušpalyte்-Vitkūnienè

A Monitoring

System

for Sustainable

Urban Mobility

Plans 


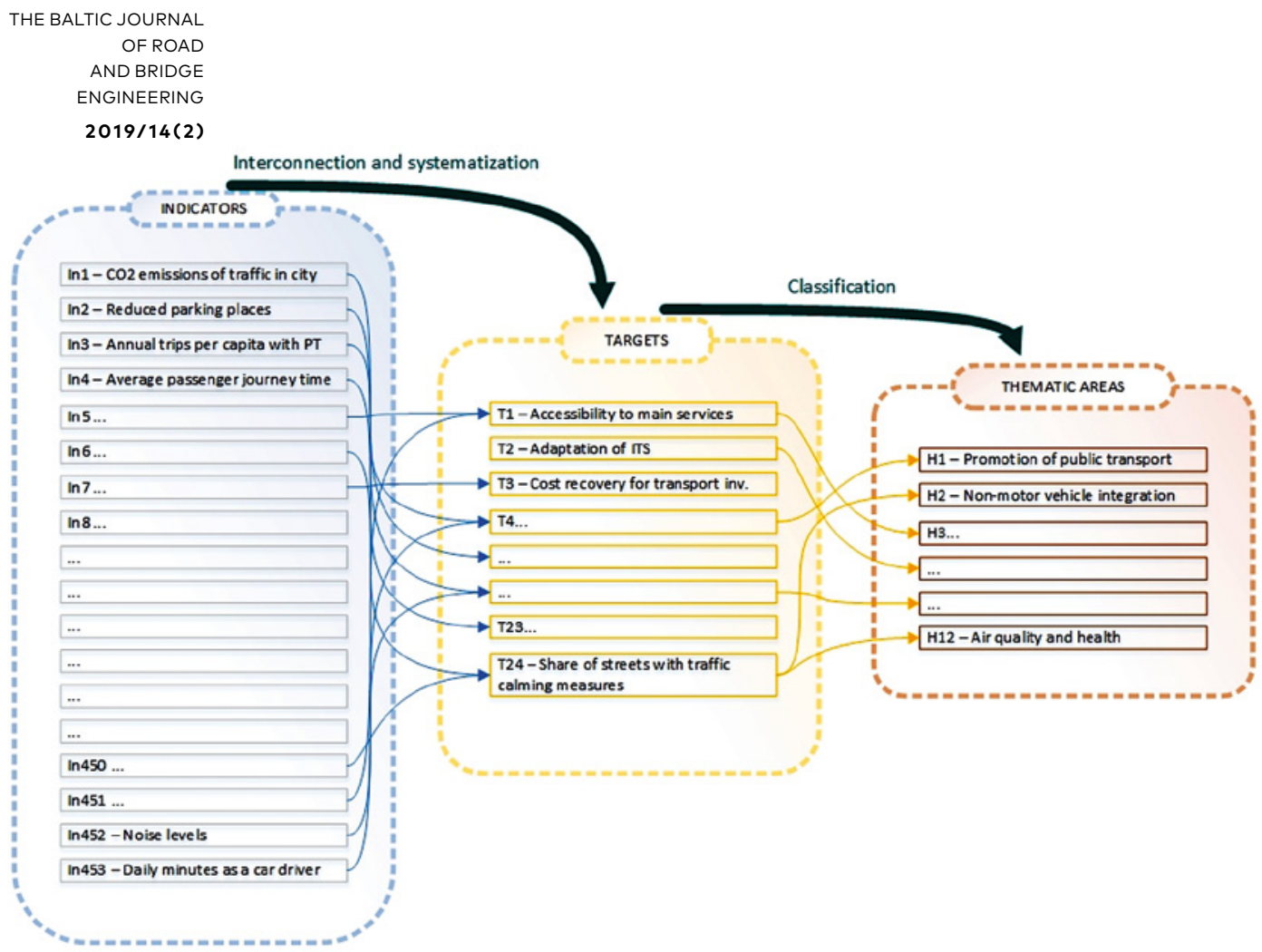

Figure 2. The principal scheme for the structure of Sustainable Urban Mobility Plans evaluation indicators and targets

- Assessing Demand for Intelligent Transport (H9).

National guidelines have been prepared by White Paper (European Commision, 2011), Communication of Efficient Urban Mobility (European Commision, 2013) and guidelines - Development and Implementing a Sustainable Urban Mobility Plan (Intelligent Energy Europe, 2014).

When systematic targeting was set up and assigned to thematic areas, some of the targets failed to be assigned to the available nine thematic areas, and thus, three new thematic areas were created based on targets:

- Accessibility and Affordability of Infrastructure (H10);

- Transport Investment Efficiency (H11);

- Air Quality and Health (H12).

The distribution of thematic areas and targets is given in Table 4 .

Dividing targets into thematic areas demonstrates that the area of Improvement in Traffic Organization and Mobility Management has a maximum of 10 targets made of 166 evaluation indicators. Consequently, the main conclusion is that mobility management has a significant 


\begin{tabular}{|c|c|c|c|c|c|c|c|c|c|c|c|c|c|c|c|}
\hline \multirow{2}{*}{$\begin{array}{l}\stackrel{n}{0} \\
0 \\
0 \\
0 \\
1\end{array}$} & \multicolumn{12}{|c|}{ Thematic Areas } & \multicolumn{2}{|c|}{ 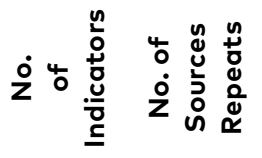 } & \multirow{2}{*}{ Source } \\
\hline & 도 & 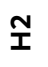 & $\stackrel{m}{I}$ & İ & 높 & 오 & 全 & $\stackrel{\infty}{I}$ & à & 음 & 폼 & $\stackrel{\mathfrak{N}}{I}$ & \multicolumn{2}{|c|}{ in Target } & \\
\hline $\mathrm{T} 1$ & & & & & + & & & & & + & & & 10 & 4 & $1,3,10,11$ \\
\hline $\mathrm{T} 2$ & & & & & & & & & + & & & & 3 & 2 & 1,2 \\
\hline T3 & & & & & & & & & & & + & & 9 & 6 & $1,5,7,11,13,16$ \\
\hline T4 & & & & & & & & & & & + & & 14 & 9 & $1,5-7,10,11,13,15,16$ \\
\hline T5 & & + & & & & & & & & & & + & 13 & 10 & $1,4,6-8,10-12,14,15$ \\
\hline T6 & & & & & & + & & + & & & & + & 23 & 15 & $1-14,16$ \\
\hline T7 & & + & & & & & + & & & & & & 23 & 7 & $1,3,6,7,10,11,15$ \\
\hline T8 & & & & & & & & & & + & & & 5 & 4 & $1,7,12,13$ \\
\hline T9 & + & & & & & & & & & + & & & 50 & 15 & $1-7,9-16$ \\
\hline T10 & & & & & + & & & & & & & & 3 & 6 & $1,3,4,6,7,13$ \\
\hline T11 & & & & & & & & + & & & & + & 19 & 12 & $3-9,11-13,15,16$ \\
\hline $\mathrm{T} 12$ & & & & & + & & & & & + & & & 6 & 4 & $1,10,11,15$ \\
\hline T13 & & & & & + & & & & & & & & 52 & 13 & $1,3-5,7,8,10-16$ \\
\hline T14 & & & + & & & & & & & & & & 24 & 13 & $1-4,6-10,12,14-16$ \\
\hline T15 & & & & & + & & & & & & & & 14 & 10 & $1,6-8,10-15$ \\
\hline T16 & & & & + & & & & & & & & & 15 & 9 & $1,5,6,8,10-13,15$ \\
\hline T17 & & & & & & + & & + & & & & + & 10 & 11 & $1-3,5-8,10,11,14,16$ \\
\hline T18 & & & & + & & & & & & & & & 13 & 11 & $1-4,8-11,13,14,16$ \\
\hline T19 & & & & & + & + & & & & & & + & 8 & 8 & $2,5,6,8,10,11,13,15$ \\
\hline T2O & & & & & + & & & & & & & + & 9 & 7 & $2-5,11,13,15$ \\
\hline T21 & & + & & & + & & & & & + & & & 42 & 15 & $1,2,4-16$ \\
\hline T22 & & & & & + & & + & & & & & & 14 & 7 & $1,5,10,11,13,15,16$ \\
\hline $\mathrm{T} 23$ & & & + & & & & & & & + & & & 42 & 15 & $1,2,4-16$ \\
\hline T24 & & + & & + & + & & & & & & & + & 8 & 7 & $4,6,7,10-12,15$ \\
\hline
\end{tabular}

impact on the overall transport system and evaluated by several indicators. Meanwhile, the thematic area of the Assessment of Demand for Intelligent Transport Systems has only one target consisting of three indicators. This show lack of the rapidly developing Intelligent Transport Systems (ITS) in cities/towns and to the shortage of knowledge about applying these systems. 
A high number of the targets attributed to the specified thematic area do not indicate the relevance or importance of the area, and thus transport experts were asked to evaluate all thematic areas using the pairwise comparison method.

\section{The significance of thematic areas}

For determining the significance of thematic areas, analytic hierarchy processes (AHPs) are used, based on primary qualitative measurements in which the results are quantified. For establishing significance, Saaty, R. (1978) \& Saaty, T. (1977) suggested using the pairwise comparison method that is a valuable tool because the experts simultaneously evaluate two thematic areas, which is an important aspect when the number of comparatives is high. The intensity of the interdependent importance of the thematic areas comparable in pairs is determined using the scale of significances proposed by Saaty, T. (1977).

The reliability of the results of the selected method is subject to the technique itself and the experts carrying out the evaluation. To employ qualified experts, they were required to be familiar with the preparation and coordination (municipal representatives) of SUMPs, research activity or the installation of mobility measures (stakeholders). The surveyed experts were asked to evaluate thematic areas for big cities, medium-sized towns and resorts. The group of resorts includes towns with the citizens under the 50 thousand. Visitors with different habits than permanent citizens mostly influence these cities. Seventeen experts, i.e. $24 \%$ of organisers, $28 \%$ of coordinators, $24 \%$ of scientists and $24 \%$ of stakeholders, carried out an expert evaluation of big cities. Sixteen experts, i.e. $19 \%$ of organisers, $55 \%$ of coordinators, $13 \%$ of researchers and $13 \%$ of stakeholders, evaluated medium-sized towns. Thirteen experts, i.e. $15 \%$ of organisers, $31 \%$ of coordinators, $23 \%$ of scientists and $31 \%$ of stakeholders, inspected resorts.

The reliability of group evaluation is an essential issue of applying the AHP method, i.e. when the opinions of the interviewed experts are compatible. In this way, statistically processing data obtained from the experts, consistency was determined by concordance coefficient $W$ proposed by Kendall (1948) and by appropriate criteria for value (Kendall \& Gibbons, 1990). Kendall (1948) proved that if the number of the evaluated objects was more than seven, the significance of the concordance coefficient could be determined using distribution. Otherwise, distribution should be used with caution because of the critical value of distribution might be higher than the calculated one despite the sufficient level of the consistency of expert opinions. 
Table 5. The ranks of evaluating thematic areas in the big cities

\begin{tabular}{|c|c|c|c|c|c|c|c|c|c|c|c|c|c|c|c|c|c|c|c|}
\hline \multirow{2}{*}{ 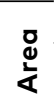 } & \multicolumn{17}{|c|}{ Expert } & \multirow{2}{*}{$\stackrel{\varepsilon}{5}$} & \multirow{2}{*}{ 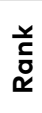 } \\
\hline & $\bar{w}$ & w & 乑 & $\stackrel{⿱ 亠 乂}{\uplus}$ & 岃 & 요 & D & $\stackrel{\infty}{\mathbf{w}}$ & 省 & 음 & $\underset{w}{\bar{u}}$ & $\underset{\mathbf{w}}{\stackrel{N}{w}}$ & $\frac{m}{w}$ & $\stackrel{ \pm}{\mathbf{w}}$ & $\frac{n}{w}$ & $\frac{\circ}{w}$ & $\underset{w}{s}$ & & \\
\hline $\mathrm{H} 1$ & 9.0 & 6.0 & 3.0 & & 1.0 & 11.0 & 10.0 & 5.0 & 10.5 & & & 7.0 & & & & 1.0 & 3.0 & 104.5 & \\
\hline $\mathrm{H} 2$ & 12.0 & 7.0 & 8.0 & 7.0 & 2.0 & 9.0 & 6.0 & 4.0 & 8.0 & 3.0 & 4.0 & 10.0 & 1.0 & 7.0 & 11.0 & 7.0 & 11.0 & 117.0 & 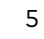 \\
\hline $\mathrm{H} 3$ & 6.0 & 2.0 & 12.0 & 6.0 & 12.0 & 12.0 & 12.0 & 9.0 & 9.0 & 12.0 & 10.0 & 8.0 & 6.0 & 10.0 & 8.0 & 6.0 & 7.0 & 147.0 & 2 \\
\hline $\mathrm{H} 4$ & 5.0 & 12.0 & 2.0 & 3.0 & 4.0 & 7.0 & 3.0 & 1.0 & 1.0 & 2.0 & 1.0 & 1.0 & 4.0 & 6.0 & 1.0 & 11.0 & 2.0 & 66.0 & 12 \\
\hline H5 & 2.0 & 3.0 & 4.0 & 1.0 & 3.0 & 8.0 & 5.0 & 7.0 & 4.0 & 7.5 & 8.0 & 4.0 & 5.0 & 5.0 & 3.0 & 5.0 & 4.0 & 78.5 & 11 \\
\hline $\mathrm{H} 6$ & 3.0 & 4.0 & 7.0 & 10.0 & 7.0 & 6.0 & 4.0 & 2.0 & 70 & 6.0 & 5.0 & 6.0 & & 8.0 & & 2.0 & 10.0 & 101.0 & 8 \\
\hline $\mathrm{H} 7$ & 1.0 & 8.0 & 10.0 & & 6.0 & 4.0 & 7.0 & 6.0 & 2.0 & 1.0 & 2.0 & 9.0 & & 1.0 & 5.0 & 12.0 & 12.0 & 93.0 & 10 \\
\hline H8 & 11.0 & 10.0 & 5.0 & 12.0 & 10.5 & 2.0 & 2.0 & 12.0 & 6.0 & 10.0 & 9.0 & 11.5 & 10.0 & 4.0 & 12.0 & 10.0 & .0 & 142.0 & 3 \\
\hline $\mathrm{H} 9$ & 7.0 & 1.0 & 9.0 & 2.0 & 10.5 & 5.0 & 8.0 & 11.0 & 10.5 & 11.0 & 12.0 & 2.0 & 12.0 & 11.0 & 4.0 & 4.0 & 6.0 & 126.0 & 4 \\
\hline $\mathrm{H} 10$ & 8.0 & 5.0 & 6.0 & & 8.0 & 3.0 & 9.0 & 9.0 & & 5.0 & 7.0 & 5.0 & 9.0 & 2.0 & 7.0 & 3.0 & 9.0 & 104.0 & 7 \\
\hline $\mathrm{H} 11$ & 4.0 & 11.0 & 11.0 & 11.0 & 5.0 & 10.0 & 11.0 & 9.0 & 12.0 & 7.5 & 11.0 & 3.0 & 11.0 & 12.0 & 9.0 & 8.0 & 8.0 & 153.5 & 1 \\
\hline $\mathrm{H} 12$ & 10.0 & 9.0 & 1.0 & 9.0 & 9.0 & 1.0 & 1.0 & 3.0 & 3.0 & 4.0 & 6.0 & 11.5 & 3.0 & 3.0 & 10.0 & 9.0 & 1.0 & 93.5 & 9 \\
\hline
\end{tabular}

As an example, for calculating the concordance coefficient and the consistency of expert opinions, the ranking results of the thematic areas of the expert evaluation conducted in the big cities are presented in Table 5.

The Eq. (1) calculates concordance coefficient $W$ :

$$
W=\frac{12 S}{q^{2} m\left(m^{2}-1\right)},
$$

where $m$ - the number of criteria, $q$ - the number of the experts, $S$ - the sum of the squares of deviations from the sum of ranks (2) for the values of each criterion (Table 5) from the total mean value (3):

$$
e_{i}=\sum_{k=1}^{q} e_{i k}
$$

where $k$ - the number of experts, $k=1,2, \ldots, \mathrm{q}$.

$$
\begin{gathered}
\bar{e}=\frac{\sum_{i=1}^{m} e_{i}}{m}, \\
S=\sum_{i=1}^{m}\left(e_{i}-\bar{e}\right)^{2} .
\end{gathered}
$$

The significance of the concordance coefficient and the consistency of evaluating groups are described by the criterion $\chi^{2}$ :

$$
\chi^{2}=W q(m-1)=\frac{12 S}{q m(m+1)} .
$$


If $\chi^{2}$ calculated by Eq. (5) is larger, than the critical value $\chi_{\text {Table }}^{2}$ obtained from Table 5 of $\chi^{2}$ distribution with a degree of freedom $v=m-1$ and significance level a chosen to be about zero, then, the estimates elicited from the experts are considered to be consistent. In this particular case when $S=8224, q=17, m=12$ and $W=0.199$, $\chi^{2}=37.21$ is calculated because of the critical value obtained from Table 5 of the Chi-Square distribution with a degree of freedom $v=m-1=11$

Table 6. The significance of thematic areas in different types of cities

\begin{tabular}{|c|c|c|c|c|}
\hline \multirow{4}{*}{$\begin{array}{l}\text { Thematic } \\
\text { area } \\
\text { No }\end{array}$} & Big Cities & Medium-Sized Towns & Resorts & \multirow{4}{*}{$\begin{array}{c}\text { Thematic } \\
\text { Area }\end{array}$} \\
\hline & \multicolumn{3}{|c|}{ Population, inhabitants } & \\
\hline & $\begin{array}{c}\text { above } \\
100000\end{array}$ & $20000-100000$ & $\begin{array}{c}\text { below } \\
20000\end{array}$ & \\
\hline & Rank & Rank & Rank & \\
\hline $\mathrm{H} 1$ & 5 & 6 & 10 & $\begin{array}{l}\text { Promotion of Public } \\
\text { Transport }\end{array}$ \\
\hline $\mathrm{H} 2$ & 8 & 5 & 4 & $\begin{array}{l}\text { Non-Motor Vehicle } \\
\text { Integration }\end{array}$ \\
\hline $\mathrm{H} 3$ & 11 & 11 & 12 & Modal Shift \\
\hline $\mathrm{H} 4$ & 1 & 1 & 1 & $\begin{array}{l}\text { Traffic Safety and Transport } \\
\text { Security }\end{array}$ \\
\hline H5 & 4 & 4 & 5 & $\begin{array}{l}\text { Improvement in Traffic } \\
\text { Organisation and Mobility } \\
\text { Management }\end{array}$ \\
\hline $\mathrm{H} 6$ & 6 & 8 & 7 & City Logistics \\
\hline $\mathrm{H7}$ & 2 & 2 & 2 & $\begin{array}{l}\text { Integration of People } \\
\text { with Special Needs }\end{array}$ \\
\hline $\mathrm{H} 8$ & 10 & 10 & 6 & $\begin{array}{l}\text { Promotion of Alternative } \\
\text { Fuels and Clean Vehicles }\end{array}$ \\
\hline $\mathrm{H} 9$ & 9 & 12 & 11 & $\begin{array}{l}\text { Assessing Demand } \\
\text { for Intelligent Transport } \\
\text { Systems }\end{array}$ \\
\hline $\mathrm{H} 10$ & 7 & 7 & 8 & $\begin{array}{l}\text { Accessibility } \\
\text { and Affordability } \\
\text { of Infrastructure }\end{array}$ \\
\hline $\mathrm{H} 11$ & 12 & 9 & 9 & $\begin{array}{l}\text { Transport Investment } \\
\text { Efficiency }\end{array}$ \\
\hline $\mathrm{H} 12$ & 3 & 3 & 3 & Air Quality and Health \\
\hline$\chi^{2}>\chi_{\text {Table }}^{2}$ & $37.21>19.68$ & $55.70>19.68$ & $64.86>19.68$ & \\
\hline
\end{tabular}


and significance level $\alpha=0.05$ is equal to $\chi_{\text {Table }}^{2}=19.68$. Hence, the estimates of the experts are consistent (37.21 > 19.68).

Calculating the values of $W$ and $\chi^{2}$ related to the evaluation of the groups of the experts and determining the consistency of group A Monitoring System for Sustainable Urban Mobility Plans estimates (Podvezko, 2005) demonstrated that the latter were consistent, and therefore the overall significance of thematic areas as the significance of the arithmetic mean of the individual experts expressed as a percentage was estimated (Table 6 and Figure 3).

Determining the significance of thematic areas has disclosed that Traffic Safety and Transport Security (H4), Integration of People with Special Needs (H7) and Air Quality and Health (H12), regardless of the size of the area, are the most important and have the same priority. Those mentioned above three thematic urban areas account for $34.7 \%$, $35.2 \%$ and $39.2 \%$ of the significance of all thematic areas, respectively. The experts praise traffic safety for the fact that road accident victims have a high economic impact - the cost of human death is estimated at EUR 647448 while injury makes EUR 58791. That founding meet with the previous traffic safety studies in such countries like Lithuania or Italy where the traffic accident level very large (Busiello, Ratkeviciute, Zilioniene, Russo, Biancardo, \& Dell'Acqua, 2014; Lithuanian Road Administration under the Ministry of Transport and Communication, 2017; Russo, Busiello, Biancardo, \& Dell'Acqua, 2014). These costs are evaluated based on damage to human health and property, expenses of research, rescue and loss of working capacity. The inclusion of people with special needs is assessed by creating alternative mobility opportunities and adapting infrastructure to people with different needs, reducing traffic congestion, increasing the attractiveness of
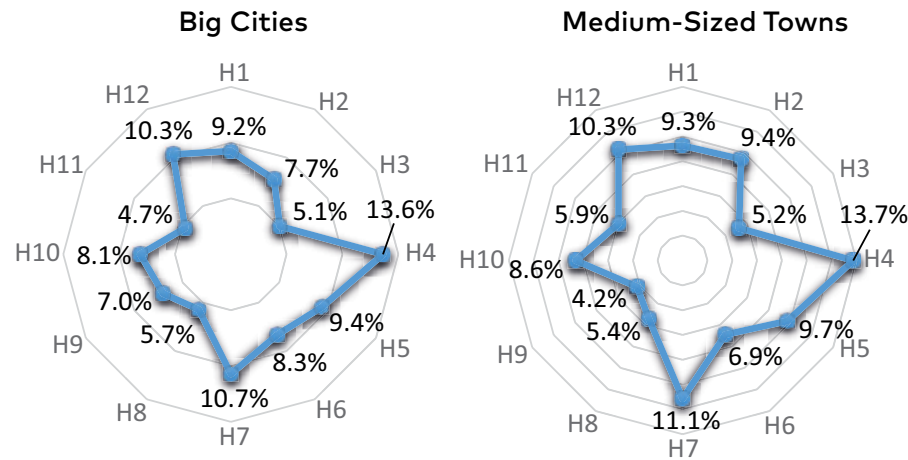

Figure 3. The significance of thematic areas in different types of cities/towns

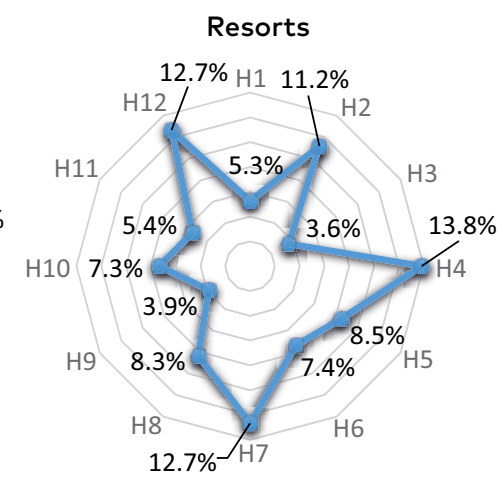


non-motorized transport infrastructure and developing universal design principles. The experts estimate that air pollution in the road transport sector of European cities poses the primary problem because the emissions of particulate matter are harmful to human health and cause fatal diseases, which makes up to $30 \%$.

The further examination of the obtained results demonstrates that Improvement in Traffic Organization and Mobility Management (H5) also has similar significance in all types of cities/towns (ranks are 4, 4 and 5 respectively). The fact mobility management explains the similar significance includes the measures having a significant impact on the transport system and peoples travel habits. For instance, effective parking space management or congestion charging makes it possible to reduce the number of vehicles on streets significantly, and the measures such as systems for multi-vehicle sharing make the transport system flexible and involve in the system persons using only a personal vehicle.

The experts consider thematic area Modal Shift (H3) rather poorly in all types of cities/towns (ranks 11, 11 and 12 respectively). This thematic area is intended to evaluate the use of different modes of transport and the number of arranged multimodal trips in the shared transport system - however, the result of the implemented mobility measures directly depending on other thematic areas. The expert evaluation confirms the fact that this thematic area has no impact on changes in the transport system, but is informative in the assessment of the overall outcome of the transport system.

In terms of the expert survey conducted in the big cities, the lowest rank was given to the thematic area of Transport Investment Efficiency (H11). The goal of sustainable mobility is to create convenient alternatives to travelling by private car, which is most frequently the development of better quality as well as more costly infrastructure (e.g. bike and pedestrian paths, bridges) or subsidised services (e.g. public transport) that do not generate financial returns. Benefits are gained referring to the indirect modes such as improving the health of people (lower health care costs), decreasing air pollution (reduced morbidity and mortality) and higher physical activity (efficiency, labour productivity).

The thematic area of Assessing Demand for Intelligent Transport Systems (H9) also received a low rank in the categories of medium-sized towns and resorts. So far, the experts feel the luck of the possibility of integrating intelligent transport systems in small towns because they do not face severe transport congestion, lack of parking spaces, and the public transport system has little potential for expansion. Hence, these are the aspects of determining the need for ITS to improve the efficiency of the transport system. 


\section{Discussion}

More and more cities in Europe have created SUMPs and included mobility measures that will address the growing problems such as congestion, air pollution, and lack of alternative transport modes, reduced physical activity and uncontrolled urban dispersion. The impact of the measures taken must be monitored regularly, identifying how they contribute to the specified objectives or how they help to assess the progress.

Different SUMP monitoring systems are debated in scientific sources, strategies and various European projects. Some of those are designed to evaluate specific urban transport systems (Chakhtoura \& Pojani, 2016; City of York Council, 2011; Perra, Sdoukopoulos, \& Pitsiava-Latinopoulou, 2017). The systems contain clearly expressed evaluation indicators that describe a transport system for a particular city/town. The introduced systems fully reflect urban planning characterised by the selected indicators thus thoroughly and sincerely evaluating the monitoring of implementation. Taking over this kind of observation for another city/town requires high matching of urban type, size and specificity. Other evaluation systems are made up of the summarised urban experience and the findings of expert working groups (CIVITAS, 2016; Intelligent Energy Europe, 2014). Another benefit of such systems points to the versatility of their application. Most often, evaluation indicators form a full spectrum, and are easy to understand and calculated, as the effectiveness of these indicators is estimated considering the available urban experience. Other systems are based on evaluation principles at the national level (Mameli \& Marletto, 2014; Ministry of Environmental of the Republic of Lithuania, 2018b; Nenseth Christiansen, \& Hald, 2012). The advantage of employing these systems is the cities evaluated through a national prism able to assist in monitoring regional and urban progress in the field of sustainable development. A comparison between cities/towns or other administrative territories become a valuable tool for planning investments and their format.

Each system examines different evaluation indicators and their values. The article creates a system for different evaluation indicators and proposes their classification by the targets assigned to the specific thematic area. The provided classification it is a universal monitoring system. The employment of the monitoring system and its evaluation indicators are recommended to assess progress in SUMP implementation. If required, new evaluation indicators are advised to be assigned to the most appropriate target to supplement the entire monitoring system.
Ušpalytè-Vitkūnienè

A Monitoring

System

for Sustainable

Urban Mobility

Plans 


\section{Conclusions}

The carried out analysis has reached the following conclusions.

1. Lithuanian Guidelines use the definitions of thematic areas on the Preparation of Sustainable Urban Plans. However, they describe only nine thematic areas. Designing a system for targets and assigning them to specific thematic areas have demonstrated that some of the targets and their evaluation indicators are just partially in line with the available thematic areas. For example, targets Improvements in Air Quality, Cost Recovery for Transport Operations, Reduction in Urban Space Consumption for Transport Infrastructure or Accessibility to the Main Services or evaluation indicators Emissions of Traffic in the City, Land Occupied by Transport Infrastructure, Percentage of Job Opportunities and Services within 45 minute Travel Distance of Residence or Percentage of Non-Car Households within 30 Minutes or 60 Minutes from the City Centre or Main Suburban Centre with Shopping \& Medical Service Provision cannot be classified as the available 9 thematic areas. For that purpose, additional thematic areas have been created based on the targets.

2. The conducted expert pairwise comparison has disclosed reliance for implementing sustainable mobility measures, regardless of the size or type of the city/town, the experts must mainly focus on the thematic areas of Traffic Safety and Transport Security (H4), Integration of People with Special Needs (H7) and Air Quality and Health (H12) and their targets. These thematic areas, by the experts, have a significant impact and produce the best result in the typical urban transport system.

3. The evaluation of the conducted analysis of research literature and various strategies has shown that the current sources mostly concentrate on (by the agreed evaluation indicators) the targets such as Improvements in Air quality, Increase in Public Transport Attractiveness, Accessibility and Affordability, Reduction in Urban Space Consumption for Transport Infrastructure, whereas Adaptation of Intelligent Transport Systems, Increase in Economic Growth, Management of Parking Spaces are given the least attention. Result of analysis is an excellent indication to city/ town executives, planners, strategists and other stakeholders as to what development priorities prevail in European cities. It is concluded, the above mentioned less attractive targets have recently been introduced due to changes in planning principles when the traditional planning of transport systems focuses on infrastructure development while sustainable mobility planning is aimed at mobility management. As a result, these targets are 
rarely evaluated because the experience of applying such mobility measures is less extensive.

4. The article has discussed twelve thematic areas to evaluate the efficiency of the transport system or to monitor the impact of the implemented mobility measures. In this manner, it is worth emphasising that every European city/town is unique, has a specific transport system, and therefore a part of indicators possible to dedicate to monitoring and evaluating particular city or town. In this case, the application of the principle formulated in the article is recommended: evaluation indicators are assigned to the created twenty four targets, and the latter are assigned to twelve thematic areas. The new principles will allow having the structured monitoring system that makes it easy to calculate the possible created effect (or vice versa) and present the obtained results employing the universal, equally applicable and understandable method.

5. Taking into account the findings of the expert evaluation of the thematic areas described in the article and considering the efficient use of available resources, the paper focuses on attaching higher importance to the thematic areas (targets and mobility measures implementing them) that have more considerable significance subject to the type and size of the city/town. The made survey involved transport experts having different interests. In consequence, it possible to conclude that the thematic areas having the greatest significances are most in agreement with the needs of the whole society. Hence, the mobility measures attributed to the aforementioned thematic areas will be strongly preferred and will have the most powerful impact on changes in public mobility habits and the overall transport system.

\section{REFERENCES}

Burinskienè, M., Gaučè, K., \& Damidavičius, J. (2017). Successful sustainable mobility measures selection. In The 10th International Conference "Environmental Engineering". Vilnius, Lithuania.

https://doi.org/10.3846/enviro.2017.102

Busiello, M., Ratkeviciute, K., Zilioniene, D., Russo, F., Biancardo, S. A., \& Dell'Acqua, G. (2014). Preliminary Canter of the Accident Rate in Italian and Lithuanian Road Networks. In Environmental Engineering. Proceedings of the International Conference on Environmental Engineering. ICEE (Vol. 9, p. 1). Vilnius Gediminas Technical University, Department of Construction Economics \& Property. https://doi.org/10.3846/enviro.2014.149 
Chakhtoura, C., \& Pojani, D. (2016). Indicator-based evaluation of sustainable transport plans: A framework for Paris and other large cities. Transport Policy, 50, 15-28. https://doi.org/10.1016/j.tranpol.2016.05.014

City of York Council (2011). City of York Local Transport Plan 2011-2031.

CIVITAS (2016). CIVITAS CAPITAL Project

Dobranskyte-Niskota, A., Perujo, A., \& Pregl, M. (2007). Indicators to assess sustainability of transport activities. European Comission, Joint Research Centre. https://doi.org/10.2788/46618

European Commision (2011). White paper, Roadmap to a single European Transport Area, Towards a competitive and resource efficient transport system. COM, 2011.

European Commision (2013). Communication from the Commission to the European Parliament, the Council, the European Economic and Social Committee and the Committee of the Regions (COM). 2013. Together towards competitive and resource - efficient urban mobility.

Gillis, D., Semanjski, I., \& Lauwers, D. (2016). How to monitor sustainable mobility in cities? Literature review in the frame of creating a set of sustainable mobility indicators. Sustainability, 8(1), 29. https://doi.org/10.3390/su8010029

Haghshenas, H., \& Vaziri, M. (2012). Urban sustainable transportation indicators for global comparison. Ecological Indicators, 15(1), 115-121. https://doi.org/10.1016/j.ecolind.2011.09.010

Intelligent Energy Europe (2016). CH4LLENGE - Addressing Key Challenges of Sustainable Urban Mobility Planning.

Joumard, R., Gudmundsson, H., \& Folkeson, L. (2011). Framework for assessing indicators of environmental impacts in the transport sector. Transportation Research Record, 2242(1), 55-63. https://doi.org/10.3141/2242-07

Karagiannakidis, D., Sdoukopoulos, A., Gavanas, N., \& Pitsiava-Latinopoulou, M. (2014). Sustainable urban mobility indicators for medium-sized cities. The case of Serres, Greece. In 2nd Conference on Sustainable Urban Mobility, Volos. Greece.

Kendall, M. G. (1948). Rank correlation methods.

Kendall, M. G., \& Gibbons, J. D. (1990). Rank correlation methods. Ed. Edward Arnold.

Li, F., Liu, X., Hu, D., Wang, R., Yang, W., Li, D., \& Zhao, D. (2009). Measurement indicators and an evaluation approach for assessing urban sustainable development: A case study for China's Jining City. Landscape and urban planning, 90(3-4), 134-142. https://doi.org/10.1016/j.landurbplan.2008.10.022

Lithuanian Road Administration under the Ministry of Transport and Communication (2017). Statistics on Road Accidents in Lithuania 2014-2017 (in Lithuanian)

Litman, T. (2007). Developing indicators for comprehensive and sustainable transport planning. Transportation Research Record, 2017(1), 10-15. https://doi.org/10.3141/2017-02

Litman, T. A. (2010). Sustainable transportation indicator data quality and availability (No. 10-2496).

Mameli, F., \& Marletto, G. (2014). Can national survey data be used to select a core set of sustainability indicators for monitoring urban mobility 
policies?. International Journal of Sustainable Transportation, 8(5), 336-359. https://doi.org/10.1080/15568318.2012.700000

Ministry of Environmental of the Republic of Lithuania (MoENV) (2018a). Comprehensive Plan of the Republic of Lithuania (in Lithuanian)

Ministry of Environmental of the Republic of Lithuania (MoENV) (2018b). Sustainable Development Goals (in Lithuanian)

Ministry of Transport and Communications of the Republic of Lithuania (2015). The Guidelines on the Preparation of Sustainable Urban Mobility Plans (in Lithuanian)

Nenseth, V., Christiansen, P., \& Hald, M. (2012). Indicators for sustainable urban mobility-Norwegian relationships and comparisons. Report, 1210, 2012.

Nourry, M. (2008). Measuring sustainable development: Some empirical evidence for France from eight alternative indicators. Ecological economics, 67(3), 441-456. https://doi.org/10.1016/j.ecolecon.2007.12.019

Olofsson, Z., Varhelyi, A., Koglin, T., \& Angjelevska, B. (2011). Measuring sustainability of transport in the city-development of an indicator-set. Bulletin/3000.

Perra, V. M., Sdoukopoulos, A., \& Pitsiava-Latinopoulou, M. (2017). Evaluation of sustainable urban mobility in the city of Thessaloniki. Transportation research procedia, 24, 329-336. https://doi.org/10.1016/j.trpro.2017.05.103

Podvezko, V. (2005). Ekspertų įverčių suderinamumas. Ūkio technologinis ir ekonominis vystymas, 11(2), 101-107.

Russo, F., Busiello, M., Biancardo, S. A., \& Dell'Acqua, G. (2014). Assessing Transferability of Highway Safety Manual Crash Prediction Models to Data from Italy. Transportation Research Record, 2433(1), 129-135. https://doi.org/10.3141/2433-15

Saaty, R. W. (1987). The analytic hierarchy process-what it is and how it is used. Mathematical modelling, 9(3-5), 161-176. https://doi.org/10.1016/0270-0255(87)90473-8

Saaty, T. L. (1977). A scaling method for priorities in hierarchical structures. Journal of mathematical psychology, 15(3), 234-281. https://doi.org/10.1016/0022-2496(77)90033-5

Shiau, T. A., \& Liu, J. S. (2013). Developing an indicator system for local governments to evaluate transport sustainability strategies. Ecological Indicators, 34, 361-371. https://doi.org/10.1016/j.ecolind.2013.06.001

United Nations Framework Convention on Climate Change (2015). The Paris Agreement

Van Audenhove, F. J., Korniichuk, O., Dauby, L., \& Pourbaix, J. (2014). The future of urban mobility 2.0: imperatives to shape extended mobility ecosystems of tomorrow.

Vivier, J., Kenworthy, J., \& Laube, F. (2001). Millennium cities database for sustainable mobility. Analyses and recommendations. Brussel: International Association of Public Transport (UITP).

Zhang, Y., \& Guindon, B. (2006). Using satellite remote sensing to survey transport-related urban sustainability: Part 1: Methodologies for indicator quantification. International Journal of Applied Earth Observation and Geoinformation, 8(3), 149-164. https://doi.org/10.1016/j.jag.2005.08.005
Jonas Damidavičius Marija Burinskienè,

Rasa

Ušpalytè-Vitkūnienè

A Monitoring

System

for Sustainable

Urban Mobility

Plans 